American Journal of Pharmaceutical Education 2019; 83 (7) Article 7031.

\title{
RESEARCH
}

\section{Training Student Pharmacists to Perform Point-of-Care Testing}

\author{
Kimberly McKeirnan, PharmD, Jennifer Czapinski, PharmD, Taylor Bertsch, PharmD, \\ Christina Buchman, PharmD, Julie Akers, PharmD \\ Washington State University College of Pharmacy, Spokane, Washington \\ Submitted February 21, 2018; accepted June 17, 2018; published September 2019.
}

\begin{abstract}
Objective. To implement training in point-of-care testing (POCT) for student pharmacists and to assess students' comfort with performing and recommending POCT for Group A streptococcus (GAS), influenza, and human immunodeficiency virus (HIV) after completion of training.

Methods. The POCT training was provided to students via a 3.5 -hour module imbedded in an intensive, week-long course. The module included a lecture with active-learning exercises and time dedicated to practicing performing nasal and throat swabs. Student performance of swab procedures was evaluated via a rubric-based skills assessment graded by a faculty member. Student pharmacists completed a pre- and post-training Likert scale survey regarding their comfort with performing and recommending POCT, and initiating appropriate treatment. Student knowledge of POCT material was evaluated via a multiple-choice examination.

Results. Most students performed proficiently on the POCT skills assessment on the first attempt (86\% achieved proficiency in performing throat swabs and $88 \%$ in performing nasal swabs), and all students were proficient by the third attempt. Student comfort and interest in performing POCT and willingness to implement POCT in their future practice significantly increased from the pre- to the post-training survey. All students achieved competency as demonstrated by achieving a score of $80 \%$ or higher on the knowledge examination on the first or second attempt.

Conclusion. Following a POCT training module, student pharmacists displayed increased willingness to perform and recommend POCT for GAS, influenza, and HIV. Expanding this training to other pharmacy schools and colleges could increase patient access to POCT.
\end{abstract}

Keywords: point-of-care testing, influenza testing, HIV testing, strep testing, community pharmacy practice

\section{INTRODUCTION}

The Clinical Laboratory Improvement Amendment of 1988 (CLIA) created increased access to tests with low risk for erroneous results by enabling facilities with a Certificate of Waiver in the United States to practice point-of-care testing (POCT). ${ }^{1}$ The fourth highest number of CLIA-waived laboratory sites are located in pharmacies, with over 9,300 currently in possession of a waiver. ${ }^{2}$ Forty-nine states currently have at least one pharmacy with an active CLIA waiver. ${ }^{2}$

Pharmacists have demonstrated that POCT for influenza, group A streptococcus (GAS) pharyngitis, and human immunodeficiency virus (HIV) can be effectively delivered in a community setting. ${ }^{3-5}$ The CDC estimated that within the United States in 2015 over one million adults and adolescents were living with HIV, and of

Corresponding Author: Kimberly McKeirnan, Washington State University, PO Box 1495, Spokane WA 9921-1495. Tel: 509-3587720. Fax: 509-358-7744. E-mail: Kimberly.mckeirnan@wsu.edu. those, 162,000 were undiagnosed. ${ }^{6}$ Additionally, during the 2015-2016 influenza season, 25 million Americans were infected with influenza, resulting in 11 million influenza-associated medical visits and 310,000 related hospitalizations. ${ }^{7}$ Acute pharyngitis accounted for an estimated 15 million patient visits in the United States in $2006 .{ }^{8}$ Group A streptococcus, or streptococcus pyogenes, is responsible for $5 \%$ to $15 \%$ of cases in adults and $20 \%$ to $30 \%$ of cases in children, and is the only acute pharyngitis that can be effectively treated with antibiotics. ${ }^{9}$ Despite these statistics, antibiotics are prescribed for an estimated $60 \%$ or more of patients with pharyngitis. $^{10}$

According to the American Association of Medical Colleges, by 2030 there will be a shortage of 42,600 to 121,300 physicians in the United States. ${ }^{11}$ Meanwhile, approximately $93 \%$ of the United States population lives within five miles of a pharmacy. ${ }^{12}$ This close proximity to pharmacists could benefit patients by increasing access to testing. ${ }^{5}$ Rapid identification of a disease may promote 


\section{American Journal of Pharmaceutical Education 2019; 83 (7) Article 7031.}

earlier initiation of antimicrobial therapy. ${ }^{13,14}$ As pharmacies across the country continue to expand their POCT services, they will highlight an important role that pharmacists can fill in their communities. ${ }^{14}$

Point of care testing is taught in some form at most colleges of pharmacy, but specific instruction in GAS, influenza, and HIV testing is taught less frequently. ${ }^{16,17}$ A 2011 survey of US schools and colleges of pharmacy found that $80 \%$ teach content regarding POCT for diabetes and cholesterol screening, while just $22 \%$ teach content related to POCT for infectious diseases. ${ }^{16}$ A 2015 survey of student pharmacists and practicing pharmacists reported that less than $20 \%$ had received any training regarding POCT for infectious diseases. ${ }^{17}$ Of the respondents who had received training, the most commonly reported POCT training for infectious diseases was for HIV, GAS, and influenza. ${ }^{17}$

Faculty at the Washington State University (WSU) College of Pharmacy and Pharmaceutical Sciences believe training students to responsibly conduct POC testing in their future practice will help improve public health by improving access to testing and disease transmission. Training in POCT is supported by the 2016 Accreditation Standards and Key Elements for the Professional Program in Pharmacy Leading to the Doctor of Pharmacy Degree ("Standards 2016") from the Accreditation Council for Pharmacy Education (ACPE). ${ }^{18}$ Standards 2016 include a requirement to teach clinical chemistry and describes that as "application of clinical laboratory data to disease state management, including screening, diagnosis, progression, and treatment evaluation." 18 The POCT content was designed to meet ACPE Standards 2016 by addressing key principles conducive to student success, including emphasis on patient-centered care, health and wellness, and population-based care. ${ }^{18}$ Efforts were also made to incorporate the Joint Commission for Pharmacy Practitioners (JCPP) Pharmacist Patient Care Process. ${ }^{19}$

The primary objective of this work was to describe the development and implementation of POCT training for student pharmacists at the Washington State University (WSU) College of Pharmacy and Pharmaceutical Sciences. Secondary objectives were to evaluate student performance on POCT content and to assess the impact of POCT training on student pharmacist comfort and confidence with performing POCT.

\section{METHODS}

The POCT training was implemented in a required clinical skills course for second-year pharmacy students. The intensive, condensed, two-credit didactic course was taught in one week at the beginning of the fall semester. This course was created in 2015 to complement the Ap- plied Patient Care laboratory course (APC) and Pharmacotherapy course taken during the same semester. The clinical skills course was intended to provide foundational knowledge and skills, which were built upon during these two courses. Training in providing several other clinical services was incorporated into the content for this course, including adult and pediatric immunization, travel medicine, and pharmacist-treatment of minor ailments and conditions. ${ }^{20}$

Out of the 36 total contact hours for this course, 3.5 hours were used for the POCT content. Course components are summarized in Table 1. Classes for all other PY2 courses were cancelled for the week because of the high number of contact hours required by the course. Cancelling other classes also allowed more faculty members to be available for teaching and assessment in the clinical skills course.

The fall 2017 cohort for the course included 124 students on the Spokane campus and 37 students on the Yakima branch campus. The team of instructors involved in the POCT training for the course included one faculty member with expertise in POCT, two academic fellows, and two residents at the Spokane campus, as well as one faculty member and one academic fellow at the Yakima campus. Content was delivered and assessed simultaneously on both campuses. All instructors involved had experience with POCT and were members of the pharmacotherapy department at WSU. One faculty member had completed the National Association of Chain Drug Stores (NACDS) Community Pharmacy-based POCT Certificate Program and the other had on-the-job training and experience. ${ }^{21}$ The three academic fellows were completing fellowships focused on teaching practice-related content. The residents were completing postgraduate year one community practice residencies at a local chain pharmacy where POCT was regularly conducted.

The educational components of the POCT section of the clinical skills course were developed to cover diseasespecific details regarding POCT for HIV, GAS pharyngitis, and influenza. The lectures and assessments were designed to meet Bloom's taxonomy levels of knowledge and application and to integrate Fink's taxonomy elements of foundational knowledge, application, and human dimension. ${ }^{22,23}$ The learning objectives for each disease state are summarized in Table 2. The overlap among learning objectives for the three disease states was intentional to help reinforce student pharmacists' patient care skills and critical thinking.

Performance on activities involved in the POCT section made up $20 \%$ of the course grade, with the knowledge assessment and skills assessment each weighted at $10 \%$ of the overall grade. The skills assessment was graded pass/ 


\section{American Journal of Pharmaceutical Education 2019; 83 (7) Article 7031.}

Table 1. Components of a Course Module to Train Student Pharmacists to Perform Point-of-Care Testing

\begin{tabular}{lr}
\hline Course Component & Time Allotted for Activity \\
\hline Influenza background, testing technique, referral criteria, and treatment & 30 minutes \\
GAS background, testing technique, referral criteria, and treatment & 30 minutes \\
HIV background, screening technique, appropriate referral agencies/organizations & 30 minutes \\
Opportunity for GAS and influenza testing technique practice & 30 minutes \\
Technique assessment for GAS and influenza testing & 30 minutes \\
Coaching, remediation for students not meeting competency on initial technique assessment & 30 minutes \\
Multiple choice knowledge examination & 30 minutes \\
Total & 3.5 hours \\
\hline
\end{tabular}

Abbreviations: HIV=human immunodeficiency virus; GAS=Group A Streptococcus

remediate, and a score of $80 \%$ or higher was required on the knowledge examination to meet competency. Students not meeting competency for either component were offered coaching and the opportunity to remediate that component.

The lecture and skills assessment took place over three hours. The first 90 minutes were dedicated to content delivery through a traditional lecture format with active-learning patient cases for small group discussion. Short video vignettes were also used to demonstrate appropriate POCT technique. After providing time for students to view the video, instructors demonstrated appropriate technique to student pharmacists, allowing for closer inspection and individual guidance for required skills. Disease epidemiology and statistics, risk factors, clinical presentation, and patient counseling were included in the lecture material. While pharmacotherapy options were not the focus of the material, guidelinebased treatment options that could be used by a pharmacist through collaborative practice agreements were discussed during the GAS and influenza sections. The content for each disease state was delivered over a period of approximately 30 minutes and aligned with the course learning objectives. An additional 30 minutes was allotted for technique practice prior to the assessment. During swab technique practice, students were required to try the nasal swab technique on themselves first and then practice this skill on at least two other students. Students also had to practice performing posterior pharynx and tonsil swabs on at least two of their peers. However, students were not limited on the number of practice attempts and were encouraged to continue practicing until the end of the allotted time. The goals of the POCT section of the course were to increase student pharmacist knowledge of POCT conducted in a community pharmacy and to increase interest among student pharmacists in incorporating POCT into their future practice. Pharmacotherapy options and disease-specific information were also included but were not the focus of this training.

Student learning was assessed via a hands-on skills competency assessment and a multiple-choice knowledge examination. The skills assessment was conducted immediately after completion of the training. The skills assessment rubric is described in Table 3. To pass the skills assessment, student pharmacists were required to demonstrate proper sample collection for the influenza test via

Table 2. Learning Objectives for Point-of-Care Testing That Were Met by Each of the Topics Presented in a Course Module to Train Student Pharmacists

\begin{tabular}{|c|c|c|c|}
\hline \multirow[b]{2}{*}{ Learning Objective } & \multicolumn{3}{|c|}{ Topic } \\
\hline & HIV & GAS & Influenza \\
\hline Recognize risk factors for acquiring the disease or condition & $\mathrm{X}$ & $\mathrm{X}$ & $\mathrm{X}$ \\
\hline Demonstrate appropriate Point-of-Care testing technique & $\mathrm{x}$ & $\mathrm{x}$ & $\mathrm{x}$ \\
\hline Identify appropriate referral agencies/organizations for patients with a reactive screening for HIV & $\mathrm{x}$ & & \\
\hline $\begin{array}{l}\text { Develop an appropriate treatment plan using disease-specific guidelines for a patient with a positive } \\
\text { testing result }\end{array}$ & & $\mathrm{x}$ & $\mathrm{x}$ \\
\hline Identify appropriate counseling strategies for patients screening reactive for HIV & $\mathrm{x}$ & & \\
\hline Identify criteria for when community pharmacy testing is not recommended & & $\mathrm{X}$ & $\mathrm{X}$ \\
\hline $\begin{array}{l}\text { Identify referral criteria for when testing should not be conducted or when the test is positive but } \\
\text { should not be treated in the pharmacy }\end{array}$ & & $\mathrm{x}$ & $\mathrm{x}$ \\
\hline
\end{tabular}

Abbreviations: HIV=human immunodeficiency virus; GAS=Group A Streptococcus pharyngitis 


\section{American Journal of Pharmaceutical Education 2019; 83 (7) Article 7031.}

Table 3. Results of Skills Assessment of Student Pharmacists After Undergoing Point-of-Care Testing Training

\begin{tabular}{|c|c|c|c|}
\hline Rapid Strep Throat Procedure Skills & $\begin{array}{c}\text { First } \\
\text { Attempt \% (No.) }\end{array}$ & $\begin{array}{c}\text { Second } \\
\text { Attempt \% (No.) }\end{array}$ & $\begin{array}{c}\text { Third } \\
\text { Attempt \% (No.) }\end{array}$ \\
\hline Introduces self to patient & $100(160)$ & $0(0)$ & $0(0)$ \\
\hline Explains procedure to patient & $99(159)$ & $1(1)$ & $0(0)$ \\
\hline Follows universal precautions, including gloves & $100(160)$ & $0(0)$ & $0(0)$ \\
\hline Tilt patient head slightly back and ask to stick tongue out & $98(156)$ & $3(4)$ & $0(0)$ \\
\hline Uses tongue blade to hold tongue down & $95(152)$ & $4(6)$ & $1(2)$ \\
\hline $\begin{array}{l}\text { Swabs back of throat (not touching teeth, cheeks, gums, } \\
\text { tongue) }\end{array}$ & $86(138)$ & $11(18)$ & $3(4)$ \\
\hline Discard biohazardous waste appropriately & $96(153)$ & $3(4)$ & $2(3)$ \\
\hline \multicolumn{4}{|l|}{ Rapid Influenza Nasal Procedure Skills } \\
\hline Introduces self to patient & 99 (159) & $0(0)$ & $0(0)$ \\
\hline Explains procedure to patient & $98(157)$ & $1(2)$ & $0(0)$ \\
\hline Follows universal precautions, including gloves & $99(158)$ & $1(1)$ & $0(0)$ \\
\hline Patient head tilted back steadied with non-dominant hand & $96(153)$ & $4(6)$ & $0(0)$ \\
\hline $\begin{array}{l}\text { Insert swab straight into nasal cavity properly and } \\
\text { rotate slightly }\end{array}$ & $88(140)$ & $12(19)$ & $0(0)$ \\
\hline Discard biohazardous waste appropriately & $94(151)$ & $5(8)$ & $0(0)$ \\
\hline
\end{tabular}

nasal swab and for GAS via a posterior pharynx and tonsil swab. Student pharmacists demonstrated swabbing skills on a student partner while being observed by one of the instructors. If students did not perform the skill competently on the first attempt, they were provided coaching and given a second, and if needed, a third attempt to successfully complete the skill. Remediation attempts were completed during the same course period unless the student pharmacist requested additional time for practice. Descriptive statistics were used to report the results of the skills assessment.

Because local HIV screening is conducted using a blood sample from a finger-stick test, a skill taught and assessed during the previous semester, this skill was not included in the assessment. Although oral HIV swab tests are available, the local National Association for the Advancement of Colored People Healthcare Committee did not recommend testing in this manner because of the long confirmation period for the western blot test. ${ }^{24}$ Instead, the Determine HIV-1/2 AG/AB Combo test (Abbott Laboratories, Lake Bluff, IL) with a shorter waiting period for confirmation or the Insti HIV Self Test (bioLytical Laboratories, Ferndale, WA) (both finger-stick tests) were recommended. ${ }^{24}$

The multiple-choice knowledge examination was conducted the week following skills training. The assessment was conducted via ExamSoft (ExamSoft Worldwide, Inc., Dallas TX) and included 12 multiple-choice questions, four from each content topic. Student pharmacists were allowed 30 minutes to complete the closed-note examination. A minimum competency score of $80 \%$ was required. Student pharmacists not achieving $80 \%$ on the examination were given a remediation attempt one week later. Opportunity for office hours with one of the instructors to discuss the examination and material were made available to student pharmacists prior to the remediation attempt. The remediation examination was also a multiple-choice question assessment intended to be the same difficulty level as the initial attempt. Quantitative statistics (averages) were used to assess and report the examination scores.

To assess student pharmacists' comfort and confidence with performing POCT and interest in providing POCT in future practice, a pre-post survey model was used and an 11-question, five-point Likert scale survey was created. The survey questions were developed by two faculty members, one with extensive experience using POCT in the community and the other who served as the main instructor for the course and had used similar survey instruments in past research, and had experience in community pharmacy practice research. ${ }^{20}$ The questions were reviewed by the members of the instruction team who were not involved in the initial question development. The survey was also pilot tested by a faculty member not involved with the project and a fourth-year student who was completing an advanced pharmacy practice experience at WSU.

The pre-training survey instrument was completed by enrolled student pharmacists prior to the beginning of the course. The survey was conducted via Qualtrics (Provo, UT) through an access link posted online in the course Blackboard Learning Management System (LMS) folder. The post-training survey was completed by student pharmacists on paper in class after the completion of 


\section{American Journal of Pharmaceutical Education 2019; 83 (7) Article 7031.}

the skills assessment. Student identifiers were not collected to prevent students from feeling coerced to complete the survey and to encourage honest answers. Students were also informed that participation was voluntary and their course grade would not be impacted by survey completion. Data were stored and analyzed in Excel. The Mann-Whitney $\mathrm{U}$ test was used to determine $p$ values. The WSU Office of Research Assurances reviewed this protocol and found the project to be exempt from Institutional Review Board review.

\section{RESULTS}

All 161 students enrolled in the course completed the knowledge examination. The class average on the assessment across both campuses was $97 \%(\mathrm{SD}=7 \%)$. Three students did not meet $80 \%$ competency on the first examination and were required to take the remediation examination one week after the first attempt. All three students achieved the minimum competency level of $80 \%$ on the second attempt. A score of $80 \%$ was recorded in the grade book for these students regardless of their actual score on the second examination attempt in accordance with our school's remediation grading policy. Student pharmacist performance in terms of achieving learning objectives is reported in Table 4.

One hundred sixty student pharmacists completed the skills assessment. One student pharmacist was absent and made up the assessment at a later date. He performed the assessment skills on a faculty member rather than a fellow student so he was not included in the skills assessment data analysis. Student pharmacists proficiently per- formed most POCT skills on the first attempt. Skills which more commonly required a second attempt included swabbing the back of the throat (14\%) and swabbing the nasal cavity (12\%). Results from the skills assessment are included in Table 3.

The pre-training survey was completed by 148 of 161 student pharmacists $(91.9 \%)$ and the post-training survey was completed by 147 student pharmacists $(91.3 \%)$. Results from the POCT pre and post-training surveys demonstrated significant changes in students' responses to all questions. Survey results are reported in Table 5.

\section{DISCUSSION}

Inclusion of a 3.5-hour training module in a weeklong, intensive, two-credit, clinical skills course was shown to increase student pharmacist comfort level in performing POCT for HIV, GAS, and influenza. Student pharmacists also demonstrated understanding of appropriateness in deciding when to initiate treatment using a collaborative drug therapy agreement and when it is appropriate to refer patients for additional care. All students eventually demonstrated competency on the knowledge examination on the first attempt, with only three students requiring a remediation attempt.

Knowledge examination competency is reviewed annually by the instructors to ensure the intensive course structure is allowing opportunity for student pharmacists to fully understand the information. Additional analysis will be conducted comparing the results of the individual knowledge examination questions to the corresponding content-specific learning objectives. If faculty members

Table 4. Knowledge Examination Results Mapped to Learning Objectives for a Course Module for Student Pharmacists on Point of Care Testing

\begin{tabular}{llccc}
\hline Topic & Question Learning Objective & $\begin{array}{c}\text { Student Performance } \\
\text { Average Score, \% } \\
\text { Mean (SD) }\end{array}$ & $\begin{array}{c}\text { Upper Quartile } \\
\text { Performance } \\
\text { Average (\%) }\end{array}$ & $\begin{array}{c}\text { Lower Quartile } \\
\text { Performance } \\
\text { Average (\%) }\end{array}$ \\
\hline Influenza & Influenza referral criteria & $98(16)$ & 100 & 95 \\
& Influenza testing technique & $97(17)$ & 100 & 95 \\
& Influenza symptoms & $96(20)$ & 100 & 95 \\
\multirow{5}{*}{ HIV } & Influenza treatment & $97(17)$ & 100 & 96 \\
& Reactive HIV screening referral & $94(24)$ & 100 & 93 \\
& HIV screening counseling & $92(27)$ & 100 & 30 \\
GAS & HIV screening technique & $57(50)$ & 100 & 87 \\
& HIV risk factors & $92(27)$ & 100 & 82 \\
& GAS criteria & $96(19)$ & 100 & 90 \\
& GAS testing technique & $100(0)$ & 100 & 97 \\
\hline
\end{tabular}

Abbreviations: $\mathrm{SD}=$ Standard Deviation; HIV=human immunodeficiency virus; GAS = Group A Streptococcus pharyngitis

Upper quartile $=$ upper $27 \%$ of students based on overall examination score

Lower quartile $=$ lower $27 \%$ of students based on overall examination score 


\section{American Journal of Pharmaceutical Education 2019; 83 (7) Article 7031.}

Table 5. Results From Surveys of Student Pharmacists Who Completed a Course Module on Point of Care Testing

\begin{tabular}{|c|c|c|c|c|c|c|c|c|}
\hline Point of Care Survey Question & Survey & $\begin{array}{l}\text { Strongly } \\
\text { Agree } \\
\% \text { (No.) }\end{array}$ & $\begin{array}{l}\text { Agree } \\
\% \text { (No.) }\end{array}$ & $\begin{array}{l}\text { Neutral } \\
\% \text { (No.) }\end{array}$ & $\begin{array}{l}\text { Disagree } \\
\% \text { (No.) }\end{array}$ & $\begin{array}{l}\text { Strongly } \\
\text { Disagree } \\
\% \text { (No.) }\end{array}$ & $\begin{array}{c}\text { Omit } \\
\%(\text { No.) }\end{array}$ & $\begin{array}{c}p \\
\text { Value }\end{array}$ \\
\hline \multirow{2}{*}{$\begin{array}{l}\text { I am comfortable testing and initiating } \\
\text { therapy for influenza. }\end{array}$} & Pre & $16(23)$ & $24(36)$ & $30(45)$ & $22(32)$ & $8(12)$ & $0(0)$ & $<.001$ \\
\hline & Post & & & & & & & \\
\hline \multirow{2}{*}{$\begin{array}{l}\text { I am comfortable testing and initiating } \\
\text { therapy for strep. }\end{array}$} & Pre & 11( & 4) & $24(35)$ & $33(49)$ & 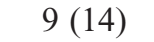 & $0(0)$ & $<.00$ \\
\hline & Post & 57( & 7) & $2(3)$ & $0(0)$ & 2( & $0(0)$ & \\
\hline \multirow{2}{*}{$\begin{array}{l}\text { I am comfortable screening and referring } \\
\text { for HIV. }\end{array}$} & Pre & 11( & 15( & 24( & 35( & $16(23)$ & $0(0)$ & $<.00$ \\
\hline & Post & 29( & 1) & 13 & 1( & 2( & 0( & \\
\hline \multirow{2}{*}{$\begin{array}{l}\text { I am comfortable differentiating between } \\
\text { initiation of treatment and referral of a } \\
\text { patient with influenza, strep, and HIV. }\end{array}$} & Pre & $8(12)$ & 17 & 28( & 36 & 11( & $0(0)$ & $<.00$ \\
\hline & Post & & & & & & & \\
\hline \multirow{2}{*}{$\begin{array}{l}\text { I am confident performing the technique } \\
\text { of a nasal swab. }\end{array}$} & Pre & & & & & & 1( & $<.00$ \\
\hline & Po & & & & & & & \\
\hline \multirow{2}{*}{$\begin{array}{l}\text { I am confident performing the technique } \\
\text { of a throat swab. }\end{array}$} & Pre & & 23 & 28( & 29 & 11( & 1( & $<.00$ \\
\hline & Po & 60( & & & & & 0 & \\
\hline \multirow{2}{*}{$\begin{array}{l}\text { I would recommend implementing testing } \\
\text { for influenza in a community } \\
\text { pharmacy. }\end{array}$} & Pre & 21( & 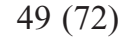 & 22( & 5( & 3( & $0(0)$ & $<.00$ \\
\hline & Post & & $33(49)$ & 3( & 0( & 2( & & \\
\hline \multirow{2}{*}{$\begin{array}{l}\text { I would recommend implementing testing } \\
\text { for strep in a community pharmacy. }\end{array}$} & Pre & $23(33)$ & $51(7$ & $20(29)$ & $4(6$ & $1(2$ & $3(4)$ & $<.001$ \\
\hline & Post & & & & & & & \\
\hline \multirow{2}{*}{$\begin{array}{l}\text { I would recommend implementing testing } \\
\text { for HIV in a community pharmacy. }\end{array}$} & Pre & $18(26)$ & $39(57)$ & $30(45)$ & $11(16)$ & $2(3$ & $1(1)$ & $<.00$ \\
\hline & Post & $47(68)$ & $35(51)$ & & $1(1)$ & $1(2$ & $1(1)$ & \\
\hline \multirow{2}{*}{$\begin{array}{l}\text { If I owned a community pharmacy I } \\
\text { would } \\
\text { implement influenza, strep, and HIV } \\
\text { testing/screening services. }\end{array}$} & Pre & $27(40)$ & $50(74)$ & $17(25)$ & $5(7)$ & $1(1)$ & $1(1)$ & $<.001$ \\
\hline & Post & $54(79)$ & $37(55)$ & $6(10)$ & $0(0)$ & $2(3)$ & $0(0)$ & \\
\hline \multirow{2}{*}{$\begin{array}{l}\text { I believe offering point-of-care training } \\
\text { services in my community is important. }\end{array}$} & Pre & $48(70)$ & $43(62)$ & $8(11)$ & $1(2)$ & $0(0)$ & $2(3)$ & $<.001$ \\
\hline & Post & 67 (99) & $29(43)$ & $1(2)$ & $0(0)$ & $2(3)$ & $0(0)$ & \\
\hline
\end{tabular}

Abbreviations: HIV=human immunodeficiency virus; GAS=Group A Streptococcus pharyngitis

identify content areas with lower examination scores, adjustments in the content delivery will be made to improve student pharmacists' understanding of the material. Faculty members are also considering adding a section regarding documentation and record keeping for POCT as that was not covered previously.

Results from the skills assessment led to plans for increased discussion and demonstration of a posterior pharynx and tonsil swab during the course next year. Nine student pharmacists needed a third attempt to reach competency on this challenging skill. The faculty members believe providing additional time for demonstration and practice may be beneficial.

This educational model could be transferred to other programs across the country. Removing a week of content from all other courses during the $\mathrm{P} 2$ fall semester was not an easy undertaking, but WSU faculty members recognized the importance of the content and agreed to postpone other classes for one week. Programs that cannot accommodate a one-week intensive schedule for PCOT training could consider modifying our approach to that of a traditional course with a laboratory component. There is also a POCT certificate program offered by NACDS. ${ }^{21}$ One of the faculty researchers holds this certification and considered adding it to this course. However, the NACDS program takes place over 20 credit hours and would not fit in the time allotted for POCT training. The training material developed at WSU is less in-depth that the NACDS POCT certificate program as it was created to be taught and assessed in a few hours while much of the content included in the NACDS program overlaps with material taught during other classes in the WSU curriculum. Another factor in this decision was cost. While the WSU material does not include a certificate, it is also not costly for students to participate. Other programs may prefer to use the NACDS certificate program in place of creating their own material if program cost and timeframe are less problematic.

Faculty members believed it was advantageous for student pharmacists to receive POCT training as early in the semester as possible, which is what led to the addition of this material to the condensed class. Some introductory 


\section{American Journal of Pharmaceutical Education 2019; 83 (7) Article 7031.}

pharmacy practice experience (IPPE) sites offer POCT, and now WSU student pharmacists will be prepared to assist with providing these services. Having student pharmacists who are confident and knowledgeable with POCT may lead to increased opportunities during IPPEs to gain real-world experience performing these clinical skills, although the faculty team does not have data to support that claim at this time.

As the practice of pharmacy continues to evolve, so should our education of future pharmacists. Many leaders in the profession believe that pharmacists are the most highly trained yet highly underutilized providers in our current health care system. ${ }^{25}$ Increasing the number of providers offering POCT has great potential to positively impact future patient access to care. Results of this research demonstrated that training student pharmacists to provide POCT improves their comfort and interest in performing POCT. After completing the POCT training, the majority of student pharmacists agreed that providing community access to these tests is important and, if they owned a community pharmacy, they would implement these services. Pharmacies across the country have implemented POCT and in addition to conducting the test, many pharmacists are also able to initiate treatment if indicated under a collaborative practice agreement or collaborative drug therapy agreement (CDTA). ${ }^{26}$ It is the role of academic pharmacists to anticipate the future of the pharmacy profession and ensure we prepare highly capable and confident professionals.

There are limitations to this research. This research involved only one program at one university. Future research should involve incorporating POCT training into additional pharmacy programs and/or other health professions education programs to provide comparative data. Additionally, the survey instrument used was not validated, and this research includes only one year of data. Refinement of the survey items as well as compiling additional data would allow faculty members to further assess students' achievement of the course learning objectives. Finally, this work was completed in Washington State, where the Washington State Pharmacy Practice Act allows pharmacists to prescribe medications through a CDTA. Thus, POCT training may be less applicable in areas where pharmacists do not conduct POCT and/or may not be able to enter into a CDTA.

\section{CONCLUSION}

Through this POCT module, student pharmacists displayed knowledge of and comfort with testing and initiating treatment for GAS and influenza and referral for HIV. Student pharmacists also reported an increased willingness to perform, provide referral for reactive screen- ing, and implement POCT for HIV in their future practice. Expanding POCT training to other colleges could increase patient access to POCT. Training future pharmacists who are knowledgeable of and comfortable with conducting POCT could benefit patients and improve public health by broadening exposure to services within the community.

\section{REFERENCES}

1. Public Health. eCFR - Code of Federal Regulations. https://www. ecfr.gov/cgi-bin/text-idx?SID=cda13b7a3e6f8691c537d4cc4ce5633 $6 \& \mathrm{mc}=$ true $\& \mathrm{tpl}=/$ ecfrbrowse/Title42/42cfr493_main_02.tpl. Accessed June 7, 2018.

2. Clinical Laboratory Improvement Amendments (CLIA) Laboratory Search. Centers for Disease Control and Prevention. https://wwwn.cdc.gov/ clia/Resources/LabSearch.aspx\#SearchResultsTop. Accessed June 7, 2017.

3. Klepser ME, Klepser DG, Dering-Anderson AM, Morse JA, Smith JK, Klepser SA. Effectiveness of a pharmacist-physician collaborative program to manage influenza-like illness. J Am Pharm Assoc. 2016:56(1):14-21.

4. Klepser DG, Klepser ME, Dering-Anderson AM, Morse JA, Smith JK, Klepser SA. Community pharmacist-physician collaborative streptococcal pharyngitis management program. J Am Pharm Assoc. 2016;56(3):323-329.

5. Gubbins PO, Klepser ME, Dering-Anderson AM, et al. Point-ofcare testing for infectious diseases: opportunities, barriers, and considerations in community pharmacy. J Am Pharm Assoc. 2014;54(2):163-171.

6. HIV/AIDS, HIV in the United States. Centers for Disease Control and Prevention. https://www.cdc.gov/hiv/statistics/overview/ ataglance.html. Accessed June 7, 2018.

7. Estimated Influenza Illnesses, Medical Visits, Hospitalizations, and Deaths Averted by Vaccination in the United States, Centers for Disease Control and Prevention. https://www.cdc.gov/flu/about/ disease/2015-16.htm. Accessed June 7, 2018.

8. Wessels, MR. Streptococcal Pharyngitis. N Engl J Med. 2011;364:648-655.

9. Ebell MH, Smith MA, Barry HC, Ives K, Carey M. The rational clinical examination: does this patient have strep throat? JAMA. 2000;284:2912-2918.

10. Schroeck JL, Ruh CA, Sellick JA, Ott MC, Mattappallil A, Mergenhagen KA. Factors associated with antibiotic misuse in outpatient treatment for upper respiratory tract infections. Antimicrob Agents Chemother. 2015;59:3848-3852.

11. IHS Inc. The Complexities of Physician Supply and Demand 2018 Update: Projections from 2016 to 2030. Prepared for Association of American Medical Colleges. Washington, DC: Association of American Medical Colleges; 2018. 12. National Association of Chain Drug Stores (NACDS). 20112012 chain pharmacy industry profile. NACDS, Alexandria, VA; 2011.

13. Davies J, Gordon CL, Tong SYC, Baird RW, Davis JS. Impact of results of a rapid staphylococcus aureus diagnostic test on pescribing of antibiotics for patients with clustered gram-positive cocci in blood cultures. J Clin Microbiol. 2012;50(6):2056-2058.

14. Klepser ME, Adams AJ, Klepser DG. Antimicrobial stewardship in outpatient settings: leveraging innovative physician-pharmacist collaborations to reduce antibiotic resistance. Health Secur. 2015;13(3):166-173. 


\section{American Journal of Pharmaceutical Education 2019; 83 (7) Article 7031.}

15. Klepser M, Adams A, Srnis P, Mazzucco M, Klepser D. U.S. community pharmacies as CLIA-waived facilities: prevalence, dispersion, and impact on patient access to testing. Res Social Adm Pharm. 2016;12(4):614-621.

16. Freed SL, Valente CA, Hagerman JK, Klepser DG, Klepser ME. Assessment of the curricular content devoted to the application and interpretation of rapid diagnostic tests in colleges of pharmacy in the United States. Phar Educ. 2011;11(1):205-208

17. Daunais DM, Klepser ME, Ogrin BJ. Assessment of pharmacy students' and licensed pharmacists' perceived knowledge, application, and interpretation regarding rapid diagnostic tests (RDTs) for infectious diseases. Curr Pharm Teach Learn. 2015;7(1):100-105.

18. Accreditation standards and key elements for the professional program in pharmacy leading to the doctor of pharmacy degree, Standards 2016. Accreditation Council for Pharmacy Education. https://www.acpe-accredit.org/pdf/Standards2016FINAL.pdf. Accessed June 15, 2018.

19. Joint Commission of Pharmacy Practitioners. Pharmacists' patient care process. http://www.pharmacist.com/sites/default/files/ PatientCareProcess.pdf. Accessed May 20, 2018.

20. McKeirnan KC, Akers JM, Czapinski JC, Robinson JD. Using collaborative drug therapy agreements to train student pharmacists to provide clinical patient care services. Am J Pharm Educ. 2017;81(2):Article 31.

21. Community-Pharmacy-based Point-of-Care Testing Certificate Program. National Association of Chain Drug Stores Education. http://nacds.learnercommunity.com/Point-of-Care-TestingCertificate. Accessed June 11, 2018.

22. Bloom BS. Taxonomy of Educational Objectives, Handbook I:

The Cognitive Domain. New York, NY: McKay; 1956.

23. Fink LD. Creating Significant Learning Experiences. An

Integrated Approach to Designing College Courses. San Francisco, CA; Jossey-Bass; 2003.

24. National Association for the Advancement of Colored People

Chapter \#1137 Healthcare Committee. The Black Church and HIV Initiative. May 9, 2016. Spokane, WA.

25. Wasson D, Akers J. The pharmacist will see you now.

Washington State Magazine. Pullman, WA: Washington State University. 2016;15(3):31-34.

26. Collins S. Point-of-care testing: emerging market, opportunity for pharmacists. Am Pharm Ass. October 1, 2015. https:// www.pharmacist.com/point-care-testing-emerging-marketopportunity-pharmacists. Accessed June 7, 2018. 